\title{
A Challenge to Graduate Education: Better Preparation for a New Generation of College Teachers-An Executive Summary
}

\begin{abstract}
Editor's Note: Copyright 1992 by the Association of American Colleges; reprinted with permission. $A A C$ has published a monograph reporting more fully on the results and implications of this project. The monograph, The Next Generation: Preparing Graduate Students for the Professional Responsibilities of College Teachers, by James Slevin, is available for $\$ 10$ plus $\$ 4$ shipping and handling (bulk orders: $\$ 8$ each for 25-50 copies; $\$ 6$ each for $51+$ copies). Send prepaid orders only to AAC's Publications Desk, $1818 R$ Street, NW, Washington, DC 20009.
\end{abstract}

$\mathbf{O}_{\text {ver the last several years, a new }}$ wave of serious concerns about the quality of teaching in undergraduate education has emerged. While many anecdotes concerning the ineptitude or indifference of college teachers are of questionable origin-and even if true misrepresent the competence and commitment of the vast majority of professors-there can be no doubt that there are significant questions about the preparation of Ph.D. students for the work of teaching. This is especially true of new Ph.D.s in recent years.

\section{The Problem}

More and more often, deans, provosts, and presidents of teachingoriented institutions express frustration about the difficulties they experience in finding new Ph.D.s who are prepared to begin teaching in these types of institutions.

- Most doctoral candidates are socialized to think of research as the most important work they can do: that achievement of a position where research is the focus-and teaching is not-is the very definition of success in an academic career. Too often, graduate school experiences impart to new Ph.D.s the notion that teaching is an inconvenient necessity in academic life: something to be avoided or at least minimized, if possible.

- Most doctoral students experience a "culture of silence" about teaching in their departments and institutions; if they are interested in improving their own understanding of and capacities for teaching, they find no encouragement or support.

- Many new Ph.D.s are so narrowly educated they are ill-equipped to teach any course outside of their specialty, even within their field. Most certainly cannot adequately handle any significant teaching responsibilities in generaleducation programs.

- Many new Ph.D.s have little awareness of the mission and character of different kinds of institutions and the different types of students they serve. Coming out of research universities, new Ph.D.s find it very difficult to balance the activities of teaching and research in a new position and very hard to adapt to a culture that puts attention to one's students at the center of the faculty member's work.

These circumstances impelled the Association of American Colleges to undertake a project designed to improve the preparation of new Ph.D.s for the full range of responsibilities of faculty members-particularly in teaching-oriented institutions, but in research universities as well. We hoped to develop an effective and economically viable model for programs by which graduate schools, cooperating with undergraduate institutions, could attend to the developmental needs of doctoral candidates likely to undertake careers as college teachers and scholars.

\section{Key Elements of the Project}

In 1989, AAC received funding from the U.S. Department of Education's Fund for the Improvement of
Postsecondary Education for a "Program on Improving the Preparation of Graduate Students for the Professional Responsibilities of College Teachers." This project involved three pairs of graduate schools and liberal arts colleges working in collaboration. It provided Ph.D. candidates in the humanities with seminar and experiential programs designed to acquaint those students with the range of responsibilities of faculty members at teaching-oriented institutions-and to teach them about teaching. The key elements of this program included:

- seminars at the graduate institutions that addressed issues of teaching and learning, faculty roles and responsibilities, and the missions and operations of a variety of types of academic institutions.

- seminars designed by and offered in participating departments in the graduate institutions that examined more specifically questions about teaching, learning, and curriculum distinctive to particular disciplines.

- visits by the graduate students to the liberal arts colleges where they observed (and in some cases helped teach) classes, sat in on department and general faculty meetings, talked with students and faculty members, observed student advising, and generally came to understand the dynamics, values, and cultures of teaching-oriented institutions. In many cases, faculty members at the liberal arts colleges formed "mentoring" relationships with individual students.

- participation by the liberal arts college faculty members in the design and leadership of the seminars at the graduate schools.

These elements were combined in a variety of ways by the different pairs of participating institutions, depending on local needs and opportunities for involving graduate students and 
faculty members from the liberal arts colleges. In every case, however, all of these activities were present in some measure in each pair, and the models developed for attempting this kind of work are promising.

\section{The Results}

After a planning year, two of the three pairs of institutions sustained programmatic activities on their campuses for the next two years. Approximately forty students from each institution took part in the project over the course of the two years. (For a variety of reasons, the graduate school in the third pair could not sustain its commitment after the first year of campus planning; the enthusiastic reports of participating graduate students at that institution were encouraging, however.) Altogether, the program served about one hundred doctoral students.

Graduate students reported that their participation in this project was exciting, challenging, and empowering. Many said their involvementespecially their relationships with faculty members at the liberal arts colleges-shattered significant negative prejudices about faculty roles and scholarship in such institutions. A number said they rediscovered their own interests in and aspirations to teaching as a career, which often was what had motivated them to pursue a Ph.D. in the first place. Many said they felt empowered to begin talking about teaching with their colleagues and to demand that their departments begin to pay attention to preparing them for teaching. Almost all said the seminar programs, especially those offered in the departments, were immensely useful in improving their understanding of and readiness for teaching.

The effects of the project on the graduate schools also were evident. In one case, a graduate department implemented a new seminar on teaching in the discipline for all Ph.D. candidates. In another department, guidelines for graduate students' involvement in teaching were revised to emphasize that whatever teaching responsibilities they were assigned should be part of their professional training - not just a way for the university to cover courses.
Moreover, the involvement of faculty members from the liberal arts colleges with the graduate schools appeared to help faculty members from the graduate institutions better understand the kinds of institutions and careers many of their students were preparing for.

For their part, faculty members from the liberal arts colleges were presented with valuable opportunities for intellectual and professional dialogue about their fields with a new set of colleagues. Faculty members from the liberal arts colleges also remarked that having graduate students present as visitors, observers, and colleagues made them more selfconscious about their own practice as teachers and scholars. They said that discussions about teaching, curriculum, and developments in their fields were stimulated and enriched through these contacts. Several said they felt their own practice as teachers and the work of their departments was improved as a result.

\section{Findings and Recommendations}

As a result of our experience in this project, AAC offers the following findings and recommendations to colleagues in graduate and undergraduate institutions.

\section{Findings}

- Many doctoral candidates enter Ph.D. studies because they want to be college teachers, but the culture of silence about teaching that they encounter there does not recognize those aspirations and discourages their pursuit of that goal.

- Many doctoral students take their (current) teaching responsibilities seriously and want training, guidance, and support to become better teachers.

- Ph.D. candidates find that involvement in discussions about how to teach in their fields enriches their understanding of their fields as well as of teaching - and sometimes opens up new perspectives on their research.

- Participation in this kind of program need not distract graduate students from their research but may, in fact, energize and sustain them in that work.

- Graduate students find that opportunities to work with faculty members from teaching-centered colleges broadens their vision of the range of possibilities for an academic career-of opportunities for combining teaching and research in personally fulfilling ways.

\section{Recommendations}

A number of changes are called for in graduate education, and the relationships between graduate schools and undergraduate institutions must be altered to foster these changes. In order to educate a new generation of Ph.D.s to be effective in the responsibilities of faculty members in all kinds of institutions, but especially those that are teachingcentered:

- Graduate schools and departments must treat teaching as an important part of scholarship, affirming the value of and potential for fulfillment in this part of an academic's work and preparing new Ph.D.s to do this work well.

- Graduate schools and departments must clarify the purpose and role of graduate students in teaching at their own institutions. If teaching is merely a requirement laid on doctoral students to "earn their keep," new Ph.D.s will continue to get the message that teaching is of secondary importance, or even a burden. If graduate students' work in teaching is structured and supervised so it is part of their professional development, they are likely to bring a very different attitude to the work of teaching in their first jobs.

- Graduate schools should encourage and support the participation of graduate faculty members as well as administrators to effect these changes. Graduate school faculty members who are themselves good teachers and care about good teaching - and there are many of them-should be supported and rewarded for their own service in teaching (as well as research) and for training and nurturing their students to be good teachers. 
For any of this to occur, support (and pressure) also must be forthcoming from forces outside graduate schools. In particular:

- Graduate fellowship programs ought to include incentives to encourage-even require-graduate departments to attend to better preparation for teaching. Foundations and other sources of fellowship funding could and should insist on this.

- Undergraduate institutions must make evidence of preparation for teaching a much more significant factor in hiring criteria.

- Undergraduate institutions should enter into dialogue with graduate schools to make clear what they need and expect in the preparation of those who will become educators as well as scholars on their faculties.

- Finally, undergraduate institutions should be prepared to enter into partnerships with graduate schools (along the lines explored in this project) in order to facilitate the preparation of new Ph.D.s for teaching.

\section{Conclusion}

Ultimately, the agenda for reform described and supported by this report is one that demands the attention of all those concerned about the future of American higher education. If those who teach in the undergraduate classroom do not understand the processes of teaching and learning, do not care about their teaching, and do not care about the missions of their institutions and the welfare of their students, even the most elegant, appropriate, and useful curriculum will be less than fully effective. Graduate and undergradu- ate institutions, as well as foundations that provide support for the education of new Ph.D.s, must cooperate to bring about effective reform in the preparation of graduate students for the professional responsibilities of college teachers.

The challenges facing the next generation of the professoriat - to be able to teach effectively and meet the developmental needs of their students - will be greater than ever. Not only are the frontiers and contours of knowledge expanding and changing rapidly; in addition, college teachers now face a student body that is vastly more diverse in background and preparation. It is crucial that graduate education turn its attention much more fully to the task of preparing a new generation of college professors who can meet these challenges.

\title{
Only Connect: Politics and Literature 10 Years Later, 1982-92
}

\author{
Maureen Whitebrook, University of Sheffield
}

\begin{abstract}
The evidence available suggests that the method of using literature for teaching political science does work: the interesting questions are now those concerned with how the "method"the combination of politics and literature in political science teaching and research-may be systematised and disseminated for the benefit of the discipline of political science (Whitebrook 1983, 16).
\end{abstract}

That "now" was 1982-83. What I want to do ten years later is to show a somewhat paradoxical conjunction of a failure and a potential.

In 1982 I came to the United States on a semester's study leave with a research project derived in part from the literature search for my Ph.D. thesis and in part from my dissatisfaction with my own teaching program at that time. My intention was to survey the practice of teaching politics through literature at college level in the United States. The results of that research were written up in "Politics and Literature," an article that appeared in the APSA's News for Teachers of Political Science (Whitebrook 1983, 16-18).

Then $I$ argued for the teaching of politics through literature to be improved. Now I widen the argument: the discipline has moved on, to the point where the matter of what politics and literature has to offer the broader field of political theory must receive serious attention. The teaching of politics and literature continues, and it is increasingly well supported by a number of good publications. But the interesting questions have not been fully answeredsystematization has hardly happened, and there has been little benefit to the discipline as a whole from the continuing existence of a diffuse group of political scientists with a persistent interest in literary texts. But developments within that group taken in conjunction with the movements in political theory in the last decade are enough to indicate that what I advocated ten years ago is possible.

The response to my article in News for Teachers of Political Science was encouraging: more contacts and indications of what was being done across the United States, including the information that it had "inspired" a published work (Mallinckrodt 1987). And the eventual outcome of my visit and continuing contacts is the volume of collected papers, Reading Political Stories (Whitebrook 1992). So far, so good? Not so, I grudgingly respond. Ten years later-and reflecting on the 1991 APSA annual meeting-I want to return to the conclusion of that article, reconsider it, and try, again, to push onwards and outwards. 